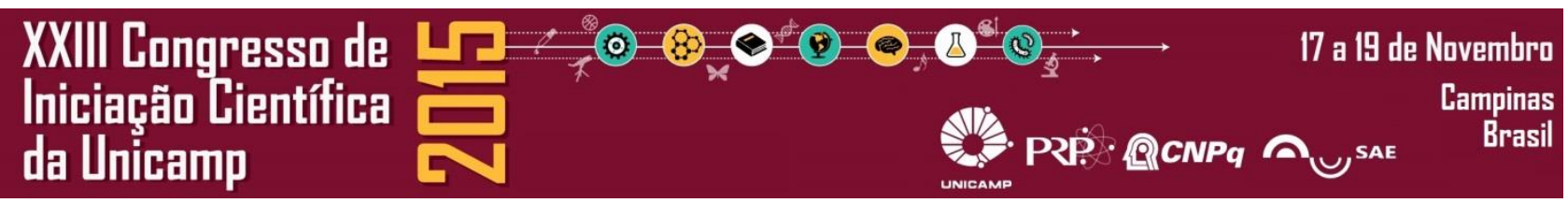

\title{
Análise do consumo de artrópodes pelos marsupiais Metachirus nudicaudatus e Didelphis aurita (Didelphidae)
}

\author{
Érica A. C. Porto (IC), Vanessa V. Kuhnen (PG), Arício X. Linhares (PQ), Eleonore Z. F. Setz (PQ)
}

\section{Resumo}

O presente trabalho teve como objetivo comparar a dieta de Didelphis aurita e Metachirus nudicaudatus. A sobreposição da dieta das duas espécies foi de $80 \%$ sendo Hymenoptera e Coleoptera as ordens mais predadas. A diferença entre as dietas deve ser reflexo de pequenas diferenças comportamentais.

Dieta, sobreposição, fezes

\section{Introdução}

Metachirus nudicaudatus e Didelphis aurita são duas espécies de marsupiais que coocorrem na Mata Atlântica. Ambas as espécies possuem hábitos similares: são terrestres, noturnas e solitárias. Entretanto, D. aurita tem maior porte com massa corporal variando entre 670 e $1882 \mathrm{~g}^{1}$, enquanto que $M$. nudicaudatus varia sua massa corporal entre 91 e $480 \mathrm{~g}^{1}$. O presente trabalho teve como objetivo descrever os artrópodes consumidos por estas duas espécies e comparar a similaridade de suas dietas.

\section{Resultados e Discussão}

Foram analisadas as fezes de 17 indivíduos de Metachirus nudicaudatus e 16 indivíduos de Didelphis aurita, capturados entre 1 de Julho de 2013 e 21 de Agosto de 2015 em Ubatuba, SP. As ordens mais consumidas pelas espécies foram Coleoptera e Hymenoptera (Fig.1).

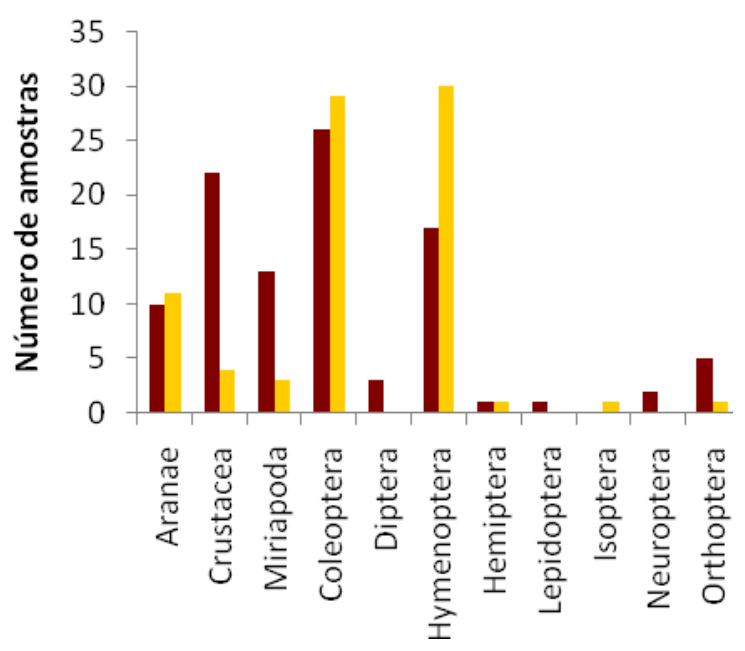

Figura 1. Consumo de artrópodes por Didelphis aurita (vinho) e Metachirus nudicaudatus (amarelo) em Ubatuba/SP, entre 2013 e 2015.
As duas espécies apresentaram um alto grau de sobreposição de suas dietas, com cerca de $80 \%$ de similaridade. D. aurita consumiu mais itens, destes Lepdoptera, Neuroptera e Diptera não foram consumidos por $M$. nudicaudatus. Enquanto que o único item consumido apenas por M. nudicaudatus foi Isoptera.

A diferença observada nas dietas pode ser reflexo da seleção de habitats diferenciada pelas duas espécies. $O$ fato de ser encontrada uma maior quantidade de Crustacea e menor quantidade de formigas nas fezes de $D$. aurita pode ser um indicador de que essa espécie tem preferência por locais mais úmidos, que favorecem as necessidades anatômicas de crustáceos $^{2}$ e nem tanto para formigas ${ }^{2}$. E como $M$. nudicaudatus apresentou uma dieta com muitos artrópodes terrestres (ex. Formicidae), é provável que essa espécie habite locais mais secos.

\section{Conclusões}

Através de nossas análises podemos concluir que $D$. aurita e $M$. nudicaudatus, apesar de serem espécies simpátricas, possuem diferenças em suas dietas. Distinguindo-se principalmente pela predação diferenciada de crustáceos e formigas, o que pode ser reflexo de um uso diferenciado do espaço. A análise indireta da dieta através das fezes se mostrou uma metodologia eficiente e que permitiu evidenciar as diferenças existentes.

\section{Agradecimentos}

O presente estudo contou com auxílio financeiro da CAPES e CNPq, além disto, a aluna E.A.C.P. realizou este trabalho através da bolsa auxílio/SAE.

\footnotetext{
${ }^{1}$ Caceres, N.C. (Org.) Os Marsupiais do Brasil: Biologia, Ecologia e Conservação. 2012, 530pp.

${ }^{2}$ Trplehorn, C. A e Jonnson, N. F. Estudo dos Insetos. 2011, 816 pp..
} 